\title{
STRATHCLYDE
}

DISCUSSION PAPERS IN ECONOMICS

GROWTH INCENTIVES AND DEVOLVED FISCAL SYSTEMS

BY

KATERINA LISENKOVA, ALASTAIR GREIG, PETER MCGREGOR, GRAEME ROY AND J KIM SWALES

No $20-09$

DEPARTMENT OF ECONOMICS

UNIVERSITY OF STRATHCLYDE GLASGOW 


\title{
Growth Incentives and Devolved Fiscal Systems*
}

By

\author{
Katerina Lisenkova \\ Alastair Greig \\ Peter G. McGregor \\ Graeme Roy \\ and \\ J. Kim Swales
}

Fraser of Allander Institute

Department of Economics, University of Strathclyde.

*The authors are grateful to participants at the European Regional Science Association Conference, Cork, 2018, and the International Input Output Conference, Glasgow, 2019, for comments on earlier versions of this paper. 


\begin{abstract}
This paper explores the characteristics of a range of stylised devolved fiscal systems which have been applied, or proposed, as a means of funding the devolved Scottish Government. The central aim is to identify those fiscal mechanisms that most effectively incentivise the pursuit of growth promoting policies by the regional government. This implies identifying the extent to which different fiscal arrangements reinforce effective local growth policies by resulting in increased devolved budgets. Simulations using an intertemporal, computable general equilibrium model for Scotland, fail to rank uniquely a range of devolved fiscal systems on this criterion over a range of demand- and supply-side policy interventions. Moreover, rather counter-intuitively, tax-sharing regimes do not necessarily improve growth incentives relative to more basic block grants.
\end{abstract}

Keywords: Regional fiscal autonomy; regional fiscal systems; applied general equilibrium.

JEL codes: D58, R13, R15, H24, H71 


\section{Introduction and background}

Until very recently the budgets for the UK devolved authorities in Northern Ireland, Scotland and Wales were primarily funded through a block grant from the central government. The levels of these grants were unrelated to the tax revenue raised within the associated territories. However, for those policy areas for which they have responsibility, these devolved authorities had, and still have, complete freedom to spend their budgets in ways which match their local priorities. There is no imposed ring-fencing from central government. Moreover, the hard budget constraint, together with limited borrowing powers, enforced financial accountability.

Nevertheless, the Scottish Government has argued that this fiscal mechanism restricts Scottish growth. In particular, if Scotland were to raise all its own revenue, in a system of full fiscal responsibility, this "... would provide the Scottish Government with greater ability to capture, and recycle, the benefits of successful policy approaches - in the form of increased tax receipts and reduced welfare payments - providing the opportunity for the full fiscal benefits (or costs) of any major policy changes to accrue to the Scottish budget" (Scottish Government, 2017).

As a result of promises made before the unsuccessful Scottish Independence referendum in 2014, there have been negotiations with the UK government resulting in an increased degree of devolved revenues, with discussions still continuing. Similar, but separate, negotiations have been ongoing with the asymmetrically devolved Northern Irish and Welsh administrations. There are a number of channels through which fiscal decentralisation could influence economic outcomes, so that making the devolved authorities responsible for funding local expenditure through local taxation could stimulate economic activity (MartinezVazquez and McNab, 2003). At the very least, such a system will increase the value that both a rational voter, and a budget-maximising local politician, would attach to growth-inducing policies as against present public consumption.

With greater fiscal devolution, concern typically centres around the trade-off between incentives, risk sharing and cumulative processes that could deplete the tax base of those regions most in need of public expenditure. However, in this paper we look at a more fundamental issue; even if it were desirable, how straightforward is it to devise such fiscal incentives? Moreover, how big is the incentive that they deliver? Specifically, we analyse the impact of generic demand and supply-side policies on devolved public sector budgets across a number of devolved fiscal mechanisms in a general equilibrium setting. These include simulations incorporating the macroeconomic impact of adjusting public expenditure to changes in the devolved budgets.

Whilst these issues have particular resonance in the UK, they are of importance for an understanding of a key aspect of devolved fiscal systems in general. The analysis has wide applicability in that it considers various degrees of fiscal autonomy, but the specific details of particular fiscal mechanisms and economic conditions can play a key role in determining the 
impact. Our focus is on an individual UK devolved region, Scotland. All of the schemes analysed in this paper have either been argued for, or actually applied in, Scotland as part of the UK's devolved fiscal arrangements.

\section{Overview}

Our primary focus is the extent to which different devolved systems fiscally reward (and therefore encourage) strategies that increase local economic activity. Envisage $j$ alternative devolved fiscal systems, each delivering a regional budget, $b_{j}$, depending on the values of the elements of a vector, $\varrho$, of local economic and demographic variables, so that:

$$
b_{j}=b_{j}(\underline{\rho})
$$

The variables in the $\varrho$ vector can be influenced by demand- or supply-side local policy interventions aimed at stimulating economic output. Examples of such policies are: improvements in export promotion; better targeting of skill training; and reductions in commercial red tape. ${ }^{1}$ The impact of such an intervention will depend on the strength of the policy and the economic environment in which it is applied.

Imagine that we have $k$ types of policy interventions with their strength identified generically as $\pi_{k}$, and that there are $\mathrm{n}$ different economic environments, which we typically refer to as model configurations. ${ }^{2}$ This means that where policy, $k$, is applied in an economy, $n$, the outcome in terms of key endogenous variables can be represented as:

$$
\underline{\rho}=e_{n}\left(\pi_{k}\right)
$$

Putting together these two steps, the procedure can be represented as:

$$
b_{j}=b_{j}\left(e_{n}\left(\pi_{k}\right)\right)
$$

Equation (3) shows the chain that links the change in policy, $k$, delivered to a devolved economy configured as $n$ to the impact on the devolved budget under the fiscal mechanism $j$. An alternative way of expressing this is:

\footnotetext{
${ }^{1}$ Our concern is with policies delivered in the context of a specific, fixed, tax framework. We do not investigate the effect a devolved authority's ability to vary exogenously aggregate local public expenditure or to manipulate tax rates. We restrict ourselves to considering only the fiscal interaction between the devolved region and the national government.

${ }^{2}$ Different model configurations could include aspects such as the economy's openness to trade, the nature of the labour market or the determination of investment. In the present paper only the time scale under consideration is varied but in future work we wish to test the sensitivity of the results to a wider range of differential model configurations.
} 
(4) $\frac{d \dot{b}_{j}}{d \dot{\pi}_{k, n}}=\sum_{i} \frac{\partial \dot{b}_{j}}{\partial \dot{\rho}_{i}} \frac{\partial \dot{\rho}_{i}}{\partial \dot{\pi}_{k, n}}$

where $\rho_{i}$ is the $i$ th element of the vector $\varrho$ and the dot notation indicates proportionate changes, so that, for example, $\dot{b}_{j}=\frac{b_{j, t}}{b_{j, 0}}$. $^{3}$ Equation (4) can be expressed in matrix form as:

(5) $\quad Q=B \Pi$

In equation (5) $Q$ is a $j X q$ matrix where $\mathrm{j}$ the number of fiscal schemes and $q$ is the $k X n$ number of policy/economic model configurations. The entry in the $r$ th row and the sth column in the $Q$ matrix is the value of $\frac{d \dot{b}_{r}}{d \dot{\pi}_{s}}$ : that is, the sensitivity of the devolved budget under the fiscal mechanism $r$ to changes in the strength of economy/policy combination s. $B$ and $\Pi$ are $\mathrm{j} X \mathrm{i}$ and $\mathrm{i} X \mathrm{q}$ matrices. The entries in the $r$ th row and the sth column of these matrices are $\frac{\partial \dot{b}_{r}}{\partial \dot{\rho}_{s}}$ and $\frac{\partial \dot{\rho}_{s}}{\partial \dot{\pi}_{r}}$ respectively.

In the discussion that follows, we use the matrix form as a convenient way to tabulate the various responses of the devolved budgets and economic variables. In Section 3 we identify the key endogenous economic and demographic variables that determine the devolved budgets for the fiscal mechanisms under consideration. This allows the construction of the $B$ matrix. In Section 4 we populate the $\Pi$ matrix using CGE simulation results which show the short- and long-run impacts of demand and supply-side stimuli on elements of the $\rho$ vector. Section 5 constructs the resultant $Q$ matrix and Section 6 extends the analysis by incorporating the impact of the changes in devolved government expenditure generated by the different fiscal schemes. Section 7 is a short discussion and conclusion.

\section{Regional Fiscal Systems: The B Matrix}

We locate this analysis within a devolved fiscal system in which responsibility for delivering public goods in the devolved region is divided between the national government and the devolved authority. We focus here solely on the way in which the budget to the devolved authority is determined and in particular the degree to which this encourages policy decisions that will increase local economic activity. We consider three main devolved fiscal mechanisms; block grant, tax-sharing and full tax autonomy.

In the block grant systems, the devolved authority is funded solely by a transfer from the central government. This transfer is not directly related to the tax revenue raised in the

3 Essentially, it is more convenient in our analysis to express equation (1) and (2) in terms of indices. 
devolved territory. Tax sharing mechanisms are intermediate cases in which some sharing of the local tax base between the national and devolved governments operates in conjunction with an adjusted block grant. Finally, in full tax autonomy we assume that the devolved authority's collects all the tax revenue raised within its own territory and after returning a fixed amount to the central authorities has the remainder as the devolved budget. We do not consider needs-based grant systems which we take to be antithetical to the encouragement of growth from the standpoint of standard economic theory.

Formulae specifying the particular devolved fiscal mechanisms, including a number of variants, are shown in Table 1, where the absolute value for the initial devolved budget is $b_{0}$. Note that individual fiscal mechanisms are identified by the appropriate subscript. Typically we are interested in the proportionate changes in the budget, which are the values in Table 1 divided by the initial value.

\section{[Table 1 near here.]}

It will prove useful to express the appropriate regional tax base in time period $t, \tau_{t}^{Z}$, as:

$$
\tau_{t}^{Z}=p_{t} \gamma_{t} \varepsilon_{t} \lambda_{t}^{Z}
$$

In equation (6), $p$ is the regional population and $\gamma$ is the participation rate, which is the ratio of the labour force (employed and unemployed) to the population as a whole. The variable $\varepsilon$ is the employment rate, which is the share of employees in the labour force; by definition, $\varepsilon$ is also equal to one minus the unemployment rate. Finally $\lambda^{Z}$ is the relevant tax base per employee. This tax base varies between devolved fiscal schemes. Here we will be concerned either with the total (full) or shared tax base, which we identify with the superscripts $Z=F, S$ respectively. The variables on the RHS of the identity given as equation (6) can be thought to comprise the elements of the $\underline{\rho}$ vector discussed in Section $2 .{ }^{4}$

Table 2 identifies the $B$ matrix introduced in equation (5) for the fiscal mechanisms that we study in this paper. Each row gives the responsiveness of the devolved budget under that fiscal scheme to changes in each of the endogenous local variables which comprise the individual elements, $\rho_{i}$, of the $\rho$ vector. In the present paper we take the value of $\gamma$, the participation rate, to be fixed, determined by demographic factors. This implies that the percentage changes in the population and the labour force are the same and that we do not need to consider changes in $\gamma .{ }^{5}$ We next explain each of the entries in Table 2.

\footnotetext{
${ }^{4}$ The tax base is expressed in this way for analytical convenience. It could be defined in greater detail or in a different way.

${ }^{5}$ This means that the reaction of employment to short-run variations in labour demand occurs only through changes in the employment rate (with a corresponding change in the unemployment rate) and that the
} 


\section{[Table 2 near here.]}

\subsection{Block grant systems}

Under the block grant approach we consider two specific schemes. These are the basic block grant scheme and the fixed per-capita grant.

\subsubsection{Basic block grant $\left(b_{B}\right)$.}

This is a fiscal transfer from the central government to the devolved authority that is fixed in nominal terms. Therefore under the basic block grant system the devolved budget in time period $\mathrm{t}, b_{B, t}$, is exactly the same as in the base year so that:

(7) $\quad \dot{b}_{B}=0$

An important issue is that the price level in the rest of the nation, here the rest of the UK (RUK) is the numeraire. The basic block grant therefore transfers to the devolved administration an amount that is constant, measured in RUK prices. The initial fiscal transfer mechanism that applied to the devolved UK regions, that is Northern Ireland, Scotland and Wales, was driven by the Barnett formula (Keep, 2018). Equation (7) shows how this formula would apply were the economy in RUK static. For the basic block grant the entries in the $B$ matrix are shown in row 1 of Table 2 and all are zero. The grant is unaffected by changes in any of these variables.

\subsubsection{Fixed per capita grant, $\left(b_{B C}\right)$.}

An alternative block grant formulation is to fix the block grant per head of population. This is particularly relevant here because evidence suggests that this is the actual outcome that the Barnett formula delivered whilst it operated in Scotland (Christie and Swales, 2010). This implies that:

$$
\dot{b}_{B C}=\dot{p}
$$

From equation (8) we derive, $\frac{\partial \dot{b}_{B C}}{\partial \dot{p}}=1$ which is reflected in row 2 of the $B$ matrix, which has only that single non-zero entry. This implies that a proportionate change in population generates an equal proportionate change in the budget, with changes in all other endogenous economic variables having zero impact.

demographic characteristics of migrants are the same as those of the initial regional population. In future work, we wish to vary these assumptions, together with other aspects of the operation of the labour market. 


\subsection{Tax sharing}

We consider two tax sharing regimes. In both these schemes the devolved administration is funded partly by retained locally-generated taxes and partly by a direct grant.

\subsubsection{Basic tax sharing $\left(b_{s}\right)$.}

We denote the most straightforward scheme with the subscript $T$. In this scheme the devolved taxes make up a share, equal to $\alpha$, of the base period devolved budget, $b_{0} .^{6}$ In subsequent periods, the block grant element - the transfer from the central government remains constant and equal to $(1-\alpha) b_{0}$; the locally funded portion equals $p_{t} \gamma_{t} \varepsilon_{t} \lambda_{t}^{S}$. In the present analysis we assume that the rates at which the devolved taxes are set are fixed. The subsequent changes to its total budget therefore depend on whether the devolved tax base, $\tau^{S}$, subsequently increases or falls. Formally this can be represented as:

$$
\dot{b}_{S}=(1-\alpha)+\alpha \dot{\tau}^{S}=1+\alpha\left[\dot{p} \dot{\gamma} \dot{\varepsilon} \dot{\lambda}^{S}-1\right]
$$

If the economy is initially in equilibrium, so that the original values of $\dot{p}, \dot{\gamma}, \dot{\varepsilon}, \dot{\lambda}^{s}=1$, then $\frac{\partial \dot{b_{S}}}{\partial \dot{p}}, \frac{\partial \dot{b_{S}}}{\partial \dot{\varepsilon}}, \frac{\partial \dot{b_{S}}}{\partial \dot{\lambda}^{S}}=\alpha$. This is represented in row 3 of the $B$ matrix, where the Scottish $\alpha$ value of 0.37 is used.

\subsubsection{Per capita tax sharing ( $\left.b_{s c}\right)$.}

This tax-sharing scheme is included here as a stylised representation of the formula that emerged from the Smith Commission after the unsuccessful vote on Scottish independence in 2014. ${ }^{7}$ Again the formula devolves the revenues from a set of taxes which make up a proportion, $\alpha$, of the base-year budget. However, in this case the subsequent block grant element does not remain constant, but rather varies with the growth in population. The algorithm is given as:

$$
\dot{b}_{S C}=(1-\alpha)+\frac{\alpha \dot{\tau}^{S}}{\dot{p}}=1+\alpha\left(\dot{\gamma} \dot{\varepsilon} \dot{\lambda}^{S}-1\right)
$$

The formula has the property that: $\frac{\partial \dot{b_{S C}}}{\partial \dot{\varepsilon}}, \frac{\partial \dot{b}_{S C}}{\partial \dot{\lambda}^{S}}=\alpha$ and $\frac{\partial \dot{b_{S C}}}{\partial \dot{p}}=0$. This information is shown as row 4 in the $B$ matrix given as Table 2 . If there is no change in the tax base per worker, the devolved budget is then independent of changes in population. ${ }^{8}$

\footnotetext{
${ }^{6}$ In the Scottish case the value of $\alpha$ is 0.37 .

${ }^{7}$ See Bell et al (2016) and Eiser (2017) for an analysis of this scheme together with comparison with the basic tax sharing scheme favoured by HM Treasury.

${ }^{8}$ It is thought that in negotiations around the formula the Scottish Government were concerned about future reductions in the Scottish population, relative to the UK as a whole.
} 


\subsection{Full tax autonomy $\left(b_{F}\right)$.}

Here we consider the case where the devolved authority has full tax autonomy (but limited borrowing powers). Though there are few examples of regional economies that have such autonomy, a stylised representation of devolved full fiscal autonomy provides a useful limiting case. The devolved region returns a proportion of the base period tax revenue raised in the region to the central government as its contribution to centrally determined public expenditure. Here this base year payment from the devolved to the central government is expressed as a ratio, $\beta$, of the base year budget, $b_{0} .{ }^{9}$ In subsequent periods this payment is maintained at its base-year nominal value. Again the devolved authority is assumed to have no control over tax rates, so that changes in the budget are determined by changes in the total tax base, $\dot{\tau}^{F}$ :

$$
\dot{b}_{F}=(1+\beta) \dot{\tau}^{F}=(1+\beta) \dot{p} \dot{\gamma} \dot{\varepsilon} \dot{\lambda}^{F}
$$

In this case the responsiveness of the devolved budget to all the endogenous variables equals 1, so that $\frac{\partial \dot{b}_{F}}{\partial \dot{p}}, \frac{\partial \dot{b}_{F}}{\partial \dot{\varepsilon}}, \frac{\partial \dot{b}_{F}}{\partial \dot{\lambda}^{F}}=1+\beta$. Again, this result is represented as row 5 of Table 2 , the $B$ matrix, where all the relevant entries have the value 1.48 .

\section{Stimulating the devolved regional economy: The $\Pi$ Matrix}

In the previous section we constructed the $B$ matrix. This reveals how the key endogenous economic variables identified in the $\varrho$ vector determine the budget under the various devolved fiscal mechanisms. In this section simulation results from a single-region Computable General Equilibrium (CGE) model are used to build a compatible $\Pi$ matrix for the short-and long-run impacts of generic demand and supply shocks. This matrix shows the effect that policies aimed at stimulating the local economy have on the key endogenous economic and demographic variables that comprise the $\varrho$ vector.

We identify the impact of two separate policy interventions. The first is a demand-side stimulus in the form of a $5 \%$ increase in regional exports; the second, a supply-side $5 \%$ improvement in labour productivity in all sectors. Both are permanent step increases applied in the context of a common modelling framework and data base.

\footnotetext{
${ }^{9}$ In the case of Scotland in 2014 the value of $\beta$ is 0.48 .
} 
The simulations use the standard AMOS CGE model for Scotland extended through the incorporation of inter-governmental transfers and a more detailed identification of individual taxes required for studying a variety of stylised regional fiscal regimes. For purely pedagogic reasons, in both cases we abstract from the administrative costs of implementing these strategies and we also hold the nominal devolved government expenditure fixed. For both policies we analyse the impact in the context of long- and short-run models of the economy. An extended set of results is given in Table 3 and the appropriate $\Pi$ matrix shown as Table 4.

\subsection{The AMOS Model}

There has been a wide range of applications of the basic AMOS model, for example Lecca et al, $(2013,2014)$. We therefore provide only a very brief outline here; a full model listing is given in Emonts-Holley et al. (2019). The variant of the model used in this paper is calibrated on a Scottish Social Accounting Matrix (SAM) for 2014, has twenty-five sectors and three domestic institutions; households, firms and government. External institutions are represented by Rest of the UK (RUK) and Rest of World (ROW). Aggregate household consumption is allocated through a CES function. In each sector gross output is generated by a nested CES production function. Each industry produces goods and services that can be exported or sold in the regional market. Intermediate and investment goods that are produced locally (in Scotland) or imported (from RUK and ROW) are considered as imperfect substitutes whose demand is determined through Armington functions.

In the short run capital stocks are fixed both in aggregate and in their sectoral disaggregation. In the long run the capital stocks adjust to their desired levels, given sectoral outputs and input prices. A related characteristic of long-run equilibrium is that the user cost of capital equals the capital rental rate, so that investment just covers depreciation. Interest rates are set in international financial markets and are taken here to be exogenous and fixed. Tax rates are held constant and for the simulations in this section government expenditure is fixed in nominal terms. That is to say the budget is set by central government through a basic block grant. In the simulations in Section 6, the alternative devolved fiscal arrangements outlined in Section 3 are used and incorporate the change in public consumption that is assumed to accompany any change in its devolved government's budget.

We do not impose strict constraints on the accumulation of foreign and public debt, because interregional transfers can sustain perpetual capital flows. However, we can track implied foreign and public sector deficits and debts and impose sustainability constraints if required. Also, inter-governmental transfers and welfare payments to households are fixed and indexed to RUK prices.

A key aspect of the model is the operation of the labour market. As with the capital stock, there is an important distinction between the short- and long-run outcomes. In the short run, the labour force is fixed so that employment only adjusts through increasing the employment 
rate. However, unlike capital, even in the short run labour can move freely across industrial sectors. In the long run, flow equilibrium inter-regional migration operates to adjust the labour force.

In our treatment of the unified labour market, three equations are critical. The first is the wage curve, where in each time period the real wage is a positive function of the employment rate (Blanchflower and Oswald, 1994; Layard et al, 1991), so that:

$$
\ln \frac{w_{t}}{c p i_{t}}=v+\theta \ln \varepsilon_{t}
$$

where $w_{t}, c p i_{t}$ and $\varepsilon_{t}$ are the regional nominal wage, consumer price index and the employment rate respectively, in period $t$.

The second is the inter-regional migration function (Treyz at al., 1993). We assume the natural population change is zero but that flow equilibrium migration occurs, driven solely by labour market conditions. Specifically:

$$
m_{t}=\mu+\phi \ln \frac{w_{t}}{c p i_{t}}+\varphi \ln \varepsilon_{t}
$$

where $m_{t}$ is the net migration rate in time period t. Equation (13) implies that net in- migration rate is a positive function of the real wage rate and the employment rate.

Finally, for the labour market to be in long-run equilibrium, there must be no net migration. Setting $m_{t}=0$ in equation (13) and rearranging gives the zero net migration (ZNM) function:

$$
\ln \frac{w_{t}}{c p i_{t}}=-\frac{\mu}{\phi}-\frac{\varphi}{\phi} \ln \varepsilon_{t}
$$

The ZNM function implies a negative relationship between the real wage and the employment rate. The logic is that equation (14) identifies the combinations of the real wage and employment rates which generate neither in- or out-migration. Essentially, for zero net migration, if the real wage is increased, the employment rate must be lower.

\subsection{Labour market impact of a stimulus}

The numerical simulations generate comparative static results. The economy is initially assumed to be in equilibrium. There is then a policy intervention which provides either a demand-or supply-side stimulus solely to the devolved region. We assume that the devolved region is small relative to the nation as a whole, so that any impact on the rest of the RUK and ROW can be ignored and is taken here to be zero. We compare the post-shock equilibrium in the devolved region to the region's initial equilibrium. 
We consider first a stylised account of how the economy reacts to an exogenous economic stimulus which increases the demand for labour. The labour market is initially taken to be in long-run equilibrium at point $A$ in Figure 1 . This is where the regional (bargained real) wage curve (BRW) and the initial labour demand curve $\left(D_{0}\right)$ intersect. ${ }^{10}$ Additionally, because the labour force is fully adjusted, net migration is zero so that the ZNM function also passes through A.

Figure 1. The impact of an increase in labour demand on the real wage and employment rates.

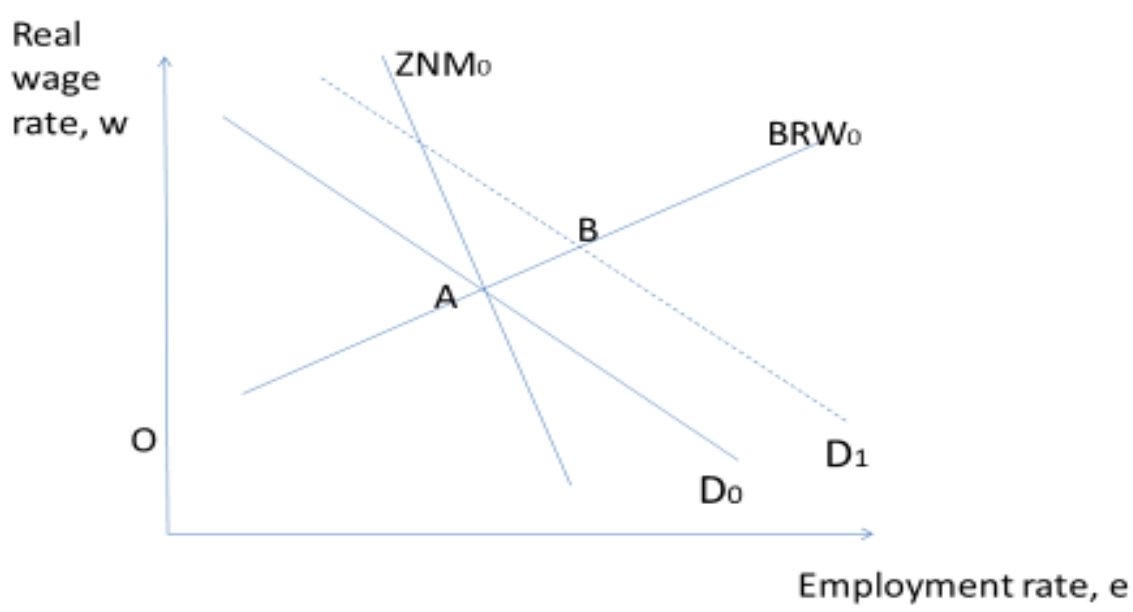

A stimulus of any sort that increases the derived demand for labour shifts the labour demand curve to the right (here to $D_{1}$ ), moving the short-run equilibrium from $A$ to $B$. This is associated with an increase in the real wage and employment rate. This stimulates in-migration and the subsequent expansion of the labour force reduces the employment rate producing a backward shift in the demand curve for labour. Given the equilibrium flow migration, this process continues until the labour demand curve returns to $D_{0}$ and the labour market equilibrium to point $A$. The real wage and employment rates therefore return to their original levels, although population and employment are permanently increased. ${ }^{11}$ Essentially the ZNM function and the wage curve tie down the long-run wage and employment rates. This is an extremely useful property of the model for our purposes.

\subsection{Simulation results: $5 \%$ export-demand stimulus}

\footnotetext{
${ }^{10}$ The labour demand curve is a general equilibrium relationship which incorporates all of the effects of a change in real wages, including those on consumption demand. While not inevitable, the labour demand curve for an open regional economy is expected to be negatively sloped, where competitiveness effects dominate the income effects of wage changes.

${ }^{11} \mathrm{Had}$ the initial shock reduced labour demand the process would have been reversed. But again long-run equilibrium reinstates the initial employment and real wage rates.
} 
In the short run, a demand-side export stimulus increases aggregate demand and shifts the labour demand curve outwards. The proportionate changes for a range of key variables are given in the first data column of Table 3. Employment and the employment rate rise. This produces an increase in the real wage and the capital rental rates, so that regional competitiveness falls, with the result that in the short run exports fail to increase by the full $5 \%$. The stimulus to investment is strong $(2.06 \%)$ but the short-run increase in GDP is only $0.19 \%$. In terms of the elements of the $\varrho$ vector, population change is zero and the employment rate increases by $0.23 \%$. The per capita shared and total tax bases rise by $1.31 \%$ and $1.09 \%$ respectively, so that the corresponding per employee figures are $1.08 \%$ and $0.86 \%$. These results are shown in the first column of Table 4 , as elements of the $\Pi$ matrix.

\section{[Table 3 near here.]}

The long-run simulation outcomes are shown in the second column of results in Table 3. As seen in Section 4.2, in-migration ultimately restores the real wage and unemployment rates to their original levels. Continuing investment also optimally adjusts the capital stock such that the initial capital rental rates are also reinstated. The outcome is a substantial increase in GDP, employment and investment of $2.50 \%, 2.31 \%$ and $2.72 \%$ respectively, accompanied by no changes in prices. This implies that in the long run exports expand by the full $5 \%$ stimulus and population increases by $2.31 \%$ with no change in the employment rate.

In the long run this CGE model operates in response to an exogenous demand shock as a linear fix-price, economy-wide model of an extended Input-Output (IO) or Social Accounting matrix (SAM) type. However, although the model is linear, this does not imply that all key variables expand by the same proportionate amount. Exports are comparatively capitalintensive, hence the proportionate increase in investment and GDP are greater than the increase in employment and population, so that there is an increase in GDP per capita of $0.19 \%$. Also because inter-regional transfers are assumed fixed, household consumption rises by less than wage income and GDP.

These differences are reflected in the differential growth rates across the various regional tax bases. Some are growing faster than population, such as indirect taxes and corporation tax, whilst others grow more slowly, such as Council Tax and VAT. Moreover, we find that as a result of the export shock, the long-run shared and total per capita tax bases both fall by $0.39 \%$ and $0.61 \%$ respectively. In this case the per employee and per capita proportionate change figures are the same. The relevant results are entered in the second column of Table 4.

\section{[Table 4 near here.]}

\subsection{Simulation results: productivity-driven supply stimulus}

Many of the options open to the devolved government increase economic activity through supply-side stimuli. These typically seek to improve regional competitiveness by increasing 
efficiency. We consider here the effects of raising labour productivity across all sectors by $5 \%$, which could be achieved through, for example, an expansion in the local provision of further and higher education.

The analysis of a supply-side shock of this type is more complex than that of the demand-side stimulus considered earlier. We characterise the improvement in efficiency as an increase, measured in efficiency units, in the labour services delivered by each employee. This means that with a given wage per worker, the cost of labour in efficiency units falls. This improvement in competitiveness stimulates output but the fall in input prices also generates complex substitution and efficiency impacts on the use of inputs.

The stimulus to productivity generates a substantial short-run boost to economic activity, as shown in the third results column of Table 3. GDP increases, by $2.19 \%$,, as also do total exports and investment, by $2.11 \%$ and $6.71 \%$ respectively. However, the short-run fixity of capital causes the demand for labour to be wage-inelastic over this time interval, meaning that although the price of labour falls in efficiency units, the rise in labour demand, again in efficiency units, is not enough to increase employment in physical units. Employment is reduced by $0.90 \%$ in the short-run, generating a corresponding fall in the employment rate, real wage and household consumption.

A central observation here is that whilst output is increasing in real terms, income tax and national insurance fall in nominal terms by $3.33 \%$ and VAT and Council Tax by $0.94 \%$ and $0.53 \%$ respectively. Whilst Corporation Tax and Indirect Taxes show increases of $4.85 \%$ and $0.61 \%$, the changes in per capita total and tax-sharing devolved tax bases are both negative at $-1.21 \%$ and $-2.60 \%$, with the corresponding per employee figures at $-0.31 \%$ and $-1.70 \%$. These results are reflected in the entries in the third column of the $\Pi$ matrix, shown here as Table 4.

In the long run, the increase in competitiveness associated with the rise in labour productivity generates a substantial boost to regional economic activity. Export and government price indices are reduced by $-3.09 \%$ and $-4.00 \%$ respectively, producing an increase in exports, GDP and employment in turn of $6.47 \%, 5.80 \%$ and $1.57 \%$. Given that the labour market is in longrun equilibrium, the employment rate returns to its initial value so that population increases by $1.57 \%$, in line with employment. Again, because of the reduction in regional prices, per capita nominal tax take falls; the reduction in total tax take per head and per employee is $1.34 \%$, less that the $-2.16 \%$ fall for those taxes devolved under the tax-sharing mechanisms. These results are entered in the fourth column in Table 4 . We have therefore derived the $4 \mathrm{X}$ $4 \Pi$ matrix for these two generic shocks applied to the two economy formulations.

\section{Variation in the impact on the devolved budgets of different policy initiatives: The $Q$ Matrix}


Multiplying the $B$ and $\Pi$ matrices, as specified in equation (5), generates the ( $5 \times 4$ ) Q matrix shown as Table 5. Each element, $q_{r, s}$, is the proportionate budget change under tax-sharing scheme $r$ that would be generated by the stimulus/economy combination $s$. Therefore, for example, the entry in the second row and second column indicates that under the per capita block grant scheme, implementing the $5 \%$ export increase generates a $2.31 \%$ long-run increase in the devolved budget. Recall that in the construction of the $\mathrm{Q}$ matrix government expenditure is actually held constant. This means that each entry shows how much the budget would change under alternative fiscal schemes but does not yet incorporate the general equilibrium impact of that change in expenditure. ${ }^{12}$

\section{[Table 5 near here.]}

Looking first at the B matrix, in Table 2, it might seem that the relative effectiveness of different devolved fiscal mechanisms should be reasonably straightforward to determine and stable across different polices. It might appear that all options are better than the basic block grant; that full tax autonomy dominates a per capita block grant; and that increasing degrees of tax sharing sees greater budget impacts. However, the $Q$ matrix (Table 5 ) reveals that once these fiscal mechanisms are combined with a range of possible policy initiatives and time periods that none of these statements is necessarily true.

An indication of the reason for these seemingly paradoxical results can be seen from the $\Pi$ matrix. There are a number of zero entries, so that many of the policy shocks influence only a restricted subset of the key variables. Further, almost half of the non-zero policy impacts on endogenous economic variables are negative. Clearly, a consistent ordering of the policies by the size of their impact on devolved budgets becomes much less likely. This difficulty is illustrated very directly in Table 5. If any two fiscal schemes are compared, the only unambiguous ordering that can be made is that the per capita block grant weakly dominates the basic block grant. Note that this means that each of the tax-sharing schemes is dominated by the basic block grant in at least one of the scenarios reported here.

It could be argued that the long-run results should carry more weight, given that the case for greater fiscal incentives is that they stimulate growth. However, even if we focus solely on the long-run impacts, which are those shown in columns 2 and 4 of Table 5, there are still unexpected results. There is no strategy that dominates all others in generating the highest budget increase. With the export shock, full tax autonomy delivers the largest long-run increase, at $2.53 \%$, whilst for the efficiency improvement the per capita block grant dominates, with a figure of $1.57 \%$. In the long run all the fiscal mechanisms dominate the per

\footnotetext{
${ }^{12}$ Therefore if the $2.31 \%$ increase in the budget, under the per capita block grant scheme and the export shock is spent with the same sectoral composition, as shown in Section 6, economic activity would increase generating a further expansion in population so that the total increase in the devolved budget would be $3.50 \%$.
} 
capita tax sharing scheme which reports negative budget changes of $-0.14 \%$ and $-0.80 \%$ for the demand- and supply-side stimulus respectively in this time period.

\section{The impact of alternative devolved fiscal schemes with recycled devolved tax revenues.}

The argument in favour of greater fiscal autonomy is not just that it provides appropriate incentives for growth promotion but that the subsequent additional revenues can be recycled to increase government expenditure, for example, further stimulating activity in the local economy. In the analysis in Sections 4 and 5, concerning the construction of the $\Pi$ and $Q$ matrices, we record the notional budgets that would have been generated but do not adjust the level of government expenditure in the simulations. That is to say, the results recorded in Tables 3, 4 and 5 do not incorporate the impact of any local recycling of changes to the budget.

Such recycling can occur in a wide range of ways. In this section we make the most straightforward adjustment. Government expenditure is varied linearly to match changes in the devolved government's budget, with public expenditure retaining the same sectoral composition. Tables 6 and 7 report the GDP and employment change respectively generated by the CGE simulations for the demand- and supply-side stimuli and the various fiscal schemes. ${ }^{13}$ These results therefore endogenise devolved government expenditure in an extremely conventional way.

Recall that there is no change in the budget under the basic block grant scheme whose entries can therefore be taken as reference points (so that the results reported in the first row of Table 6 correspond to those in the first row of Table 3 ). The deviation in results from these benchmarks indicates the impact on economic activity generated by the change in public expenditure under the different fiscal schemes. Again it is useful to concentrate on the longrun effect, shown in the second and fourth columns.

\section{[Table 6 near here.]}

For the GDP results, given in Table 6, the impact of incorporating the change in public expenditure is generally positive and can significantly enhance the simulated impact of the policy. In the short run full tax autonomy increases the impact from the benchmark $0.19 \%$ to $0.32 \%$. In the long run, with the per capita block grant schemes and full tax autonomy the effect of the policy stimulus to export demand is increased by between $35 \%$ and $40 \%$. That is to say, it is increased from the long-run benchmark $2.50 \%$ to $3.37 \%$ and $3.47 \%$ respectively. However, note that with per capita tax sharing (fourth row of Table 6), the GDP change actually falls below the benchmark value, though we would expect this given the negative entry in the $Q$ matrix.

With the labour efficiency shock, the impact of the additional devolved expenditure on the GDP figure is much more mixed. In the short run, endogenising government expenditure using

\footnotetext{
${ }^{13}$ We assume for simplicity that the government expenditure has no direct supply-side impacts, such as might be expected to accompany increased expenditure on education and health, for example.
} 
these schemes has a zero or negative impact. In the long run, under the full tax autonomy and per capita block grant schemes the effect is positive in the long run but small, increasing the overall impact by just less than $3 \%$ and just over $10 \%$ respectively (from $5.80 \%$ benchmark to $5.96 \%$ and $6.42 \%)$.

\section{[Table 7 near here.]}

For the employment effects, as shown in Table 7, the impact pattern is similar but the changes are slightly greater than for GDP. In particular, with the export demand shock, the full tax autonomy scheme increases the short run employment change from the benchmark $0.23 \%$ to $0.43 \%$, an $87 \%$ increase. In the long run the per capita block grant and the full tax autonomy schemes increase the employment effect by $45 \%$ to $50 \%$. For the labour efficiency improvement, the additional employment effects in the short run are never positive and in the long run the per capita block grant again increases the employment effect by $45 \%$, but the increase with full tax autonomy is still only around $10 \%$ and there are reductions in the impact on employment relative to the benchmark level with the tax-sharing schemes.

\section{Conclusions}

In this paper we investigate the degree to which different devolved fiscal schemes provide an incentive for politicians and voters to support policies to stimulate local economic activity. We develop a new conceptual framework to facilitate this analysis. The first element of the framework is the specification of each fiscal scheme's architecture, which incorporates the key economic determinants of the devolved government's budget (captured in the B matrix). The second element of the framework identifies the manner in which generic demand- and supply-side policies implemented by the devolved authorities impact endogenous economic variables (including those identified as key determinants of the devolved government's budget). These relationships are captured in the $\Pi$ matrix,

The interaction between the schemes' architectures and the devolved authority's policies, summarised in the $\mathrm{Q}$ matrix $(B \Pi)$ then governs the impact of disturbances on devolved budgets across a spectrum of fiscal arrangements and over two time intervals, the short and long runs. The final element in the framework identifies the effects of recycling the changes in Government revenues shown in the Q matrix through changes in the devolved authority's current expenditure.

The work is motivated, at least partly, by the policy debates in Scotland and elsewhere concerning the strength and limitations of existing and possible alternative devolved fiscal systems. The B matrix therefore incorporates stylised representations of fiscal schemes which either have been implemented, or have been proposed, as a means to determine the Scottish devolved budget; and the $\Pi$ matrix is constructed using a simulation model calibrated on Scottish data. The final element of the framework, which explicitly incorporates the endogeneity of current government spending, is also implemented through model simulation. However, whilst the treatment has a particular Scottish resonance, the issues are of a much 
more general character; the framework has quite general applicability, although the details of the $\Pi$ matrix will naturally vary across regions (as may the candidate alternative fiscal schemes articulated in the B matrix).

There are two main lessons coming from the detailed results generated in the simulations. The first is that the identification of fiscal schemes that will deliver growth incentives is less straightforward than it might seem. For the five schemes we cover, none dominates the others over the whole range of expansionary policies and time periods that we study. Moreover, in almost all cases, even taking pairs of fiscal schemes, it was not possible to unambiguously rank one as against the other when considered over these two generic policies and two time frames.

The second lesson is the relatively strong long-run performance of the per capita block grant fiscal scheme and the corresponding weak performance of the per capita tax sharing mechanism. This is of particular interest because evidence suggests that over an extended period of time the de facto determination of the Scottish budget had been as a per capita block grant. Moreover, the per capita tax sharing is the scheme that the Scottish Government successfully argued to be put in place following the close, but unsuccessful, Scottish Independence vote in 2014.

However, it is important to note that the present paper is primarily exploratory. It develops a conceptual framework with which to approach this issue and uncovers some surprising results. The analysis points strongly to a number of useful extensions that should be the focus of future research.

First, the results depend critically on endogenous changes in population, the labour supply and the wage determination process. Accordingly, the sensitivity of the results to the behaviour of migration and its composition (relative to the current population) merits further development. Similarly, while there is compelling evidence supporting the adoption of a regional wage curve relationship, such as that used in our analysis, over the longer term, experience since the Great Recession suggests that this may have broken down, and it would be useful to explore the possible consequences of this.

Second, it would be valuable to track the impact of these exogenous shocks using a periodby-period analysis and compare a selection of the adjustment paths to the long-run equilibria which are the focus of this paper. This would also provide an appropriate context in which to explore the impact of alternative fiscal regimes on the resilience and stability of regional economies.

Finally, while the single region focus considerably simplifies the analysis, extension to a multiregional context would represent a significant generalisation and permit exploration of symmetric as well as asymmetric shocks. 


\section{References}

Blanchflower, G.D., Oswald, A.J., (1994). Estimating a Wage Curve for Britain. The Economic Journal, $104,1025-43$.

Bell, D., Eiser, D., and Phillips, D. (2016) Scotland's Fiscal Framework: Assessing the Agreement, Institute of Fiscal Studies, IFS Working Paper, W16/05

Eiser, David (2017) A primer on the Scottish Parliament's new fiscal powers : what are they, how will they work, and what are the challenges?, Fraser of Allander Economic Commentary, 41 (2). pp. 2641.

Christie, A. \& Swales, J.K. (2010) The Barnett Allocation Mechanism: Formula Plus Influence?, Regional Studies, 44:6, 761-775, DOI: 10.1080/00343400903107710

Emonts-Holley T., Greig A., Lecca P., Lisenkova K., McGregor P.G. \& Swales J.K. (2019) A Scandinavian 'high-tax, high-spend' model for regions? The impact of enhanced regional fiscal autonomy, Spatial Economic Analysis, DOI: 10.1080/17421772.2019.1568536

Keep, M. (2018) The Barnett Formula, House of Commons Library, Briefing Paper

Layard, R., Nickell, S. Jackman, R., 1991. Unemployment: Macroeconomic Performance and the Labour Market. Oxford University Press, Oxford.

Lecca, P, McGregor, P \& Swales, J.K. (2013), Forward looking versus myopic regional computable general equilibrium models: how significant is the distinction?, Economic modelling, 31, 160-176.

Lecca, P., McGregor, P.G., Swales, J.K. \& Yin, Y.P (2014), Balanced budget multipliers for small open regions within a federal system: Evidence from the Scottish variable rate of income tax. Journal of Regional Science, 54(3), 402-421.

Martinez-Vazquez, J. and McNab, R.M. (2003): Fiscal Decentralization and Economic Growth, World Development 31(9), pp. 1597-1616.

Scottish Government (2017), "Arguments for Full Fiscal Autonomy", https://www.gov.scot/binaries/content/documents/govscot/publications/foi-eirrelease/2017/08/foi-17-01600/documents/foi-17-01600-rationale-full-fiscal-autonomy-pdf/foi-1701600-rationale-full-fiscal-autonomy-pdf/govscot\%3Adocument/FOI-17-01600\%2B\%2BRationale\%2Bfor\%2BFull\%2BFiscal\%2BAutonomy.pdf Submission by the Scottish Government to the Smith Commission arguing for Full Fiscal Autonomy, released under Freedom of Information, 2017.

Treyz, G.I., Rickman, D.S., Hunt, G.L. and Greenwood, M.J., 1993. The dynamics of US internal migration. Review of Economics and Statistics, 75, 209-14. 
Table 1. Stylised regional fiscal regimes

\begin{tabular}{|c|c|c|c|c|}
\hline Name & Symbol & Formula $\left(b_{z, t}\right)$ & General Description & Scottish Example \\
\hline $\begin{array}{l}\text { Simple block } \\
\text { grant }\end{array}$ & $b_{B, t}$ & $b_{0}$ & Fixed nominal budget & Barnett \\
\hline $\begin{array}{l}\text { Per capita } \\
\text { block grant }\end{array}$ & $\mathrm{b}_{\mathrm{BC}, \mathrm{t}}$ & $b_{0} \frac{p_{t}}{p_{0}}$ & Fixed per capita nominal budget & Barnett plus influence \\
\hline $\begin{array}{l}\text { Basic Tax } \\
\text { sharing }\end{array}$ & $\mathrm{b}_{\mathrm{s}, \mathrm{t}}$ & $b_{0}\left[1+\alpha\left[\frac{p_{t} \gamma_{t} \varepsilon_{t} \lambda_{t}^{S}}{p_{0} \gamma_{0} \varepsilon_{0} \lambda_{0}^{S}}-1\right]\right.$ & Partial devolved tax base with no regional population adjustment & Treasury Block Grant Adjustment \\
\hline $\begin{array}{l}\text { Per capita Tax } \\
\text { sharing }\end{array}$ & $\mathrm{b}_{\mathrm{sc}, \mathrm{t}}$ & $b_{0}\left[1+\alpha \frac{p_{t}}{p_{0}}\left[\frac{\gamma_{t} \varepsilon_{t} \lambda_{t}^{S}}{\gamma_{0} \varepsilon_{0} \lambda_{0}^{S}}-1\right]\right.$ & $\begin{array}{l}\text { Partial devolved taxes base adjusted for changes in regional } \\
\text { population. }\end{array}$ & Smith Block Grant Adjustment \\
\hline $\begin{array}{l}\text { Full Tax } \\
\text { Autonomy }\end{array}$ & $b_{F, t}$ & $b_{0}\left[\frac{p_{t} \gamma_{t} \varepsilon_{t} \lambda_{t}^{F}}{p_{0} \gamma_{0} \varepsilon_{0} \lambda_{0}^{F}}-\beta\right]$ & Budget determined solely by local tax take & Scottish Government Aspiration \\
\hline
\end{tabular}

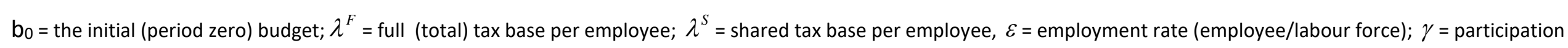

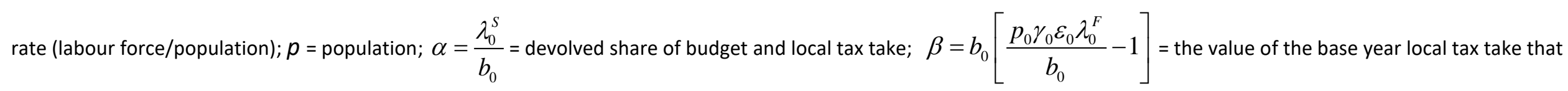

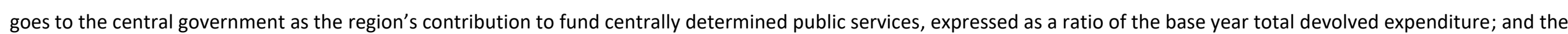
$\mathrm{t}$ subscript indicates time period. 
Table2: The B matrix: The sensitivity of the budgets under alternative devolved fiscal mechanisms to proportionate changes in

elements of the $\rho$ vector.

\begin{tabular}{|c|c|c|c|c|c|}
\hline \multicolumn{2}{|c|}{$\begin{array}{c}\text { Endogenous variables } \\
\text { Budget sensitivity }\left(\partial \dot{\rho}_{i}\right)\end{array}$} & $\dot{p}$ & $\dot{\varepsilon}$ & $\dot{\lambda}^{S}$ & $\dot{\lambda}^{F}$ \\
\hline \multirow{2}{*}{$\begin{array}{c}\text { Block Grant } \\
\text { Schemes }\end{array}$} & $\frac{\partial \dot{b}_{B}}{\partial \dot{\rho}_{i}}$ & 0 & 0 & 0 & 0 \\
\cline { 2 - 6 } & $\frac{\partial \dot{b}_{B C}}{\partial \dot{\rho}_{i}}$ & 1 & 0 & 0 & 0 \\
\hline \multirow{2}{*}{\begin{tabular}{c} 
Tax sharing \\
\cline { 2 - 6 }
\end{tabular}} & $\frac{\partial \dot{b}_{S}}{\partial \dot{\rho}_{i}}$ & 0.37 & 0.37 & 0.37 & 0 \\
\cline { 2 - 6 } & $\frac{\partial \dot{b}_{S C}}{\partial \dot{\rho}_{i}}$ & 0 & 0.37 & 0.37 & 1.48 \\
\hline \multirow{2}{*}{ Full Tax Autonomy } & $\frac{\partial \dot{b}_{F}}{\partial \dot{\rho}_{i}}$ & 1.48 & 1.48 & 0 & 0 \\
\hline
\end{tabular}

Note: For the Scottish data $\alpha=0.37$. The figure is calculated as base year (Income Tax $+50 \%$ VAT + Council Tax + Landfill Tax)/Devolved Public Expenditure. The $\beta$ value is 0.48 . 
Table 3: The impact of $5 \%$ improvements in exports and in productivity under the basic block grant system (\% changes from base.)

\begin{tabular}{|c|c|c|c|c|}
\hline Time period & Short run & Long run & Short run & Long run \\
\hline GDP (fm) & $0.19 \%$ & $2.50 \%$ & $2.19 \%$ & $5.80 \%$ \\
\hline GDP per capita & $0.19 \%$ & $0.19 \%$ & $2.19 \%$ & $4.17 \%$ \\
\hline Household Consumption & $0.29 \%$ & $1.36 \%$ & $-0.54 \%$ & $1.68 \%$ \\
\hline Investment & $2.06 \%$ & $2.72 \%$ & $6.71 \%$ & $5.14 \%$ \\
\hline Total Exports & $2.07 \%$ & $5.00 \%$ & $2.11 \%$ & $6.47 \%$ \\
\hline Total Imports & $1.93 \%$ & $2.32 \%$ & $0.44 \%$ & $0.83 \%$ \\
\hline \multicolumn{5}{|l|}{ WAGES: } \\
\hline Post tax nominal wage & $1.24 \%$ & $0.00 \%$ & $-2.45 \%$ & $-2.24 \%$ \\
\hline \multicolumn{5}{|l|}{ PRICES: } \\
\hline CPI & $0.81 \%$ & $0.00 \%$ & $-0.98 \%$ & $-2.24 \%$ \\
\hline Govnt price index & $0.84 \%$ & $0.00 \%$ & $-2.68 \%$ & $-4.00 \%$ \\
\hline Export price index & $1.43 \%$ & $0.00 \%$ & $-1.03 \%$ & $-3.09 \%$ \\
\hline Repl cost of capital & $0.72 \%$ & $0.00 \%$ & $-0.65 \%$ & $-1.78 \%$ \\
\hline User cost of capital & $0.72 \%$ & $0.00 \%$ & $-0.65 \%$ & $-1.78 \%$ \\
\hline \multicolumn{5}{|l|}{ LABOUR MARKET: } \\
\hline Unemployment level & $5.78 \%$ & $6.00 \%$ & $6.85 \%$ & $6.00 \%$ \\
\hline Unemployment Rate (pp difference) & $-0.22 \%$ & $0.00 \%$ & $0.85 \%$ & $0.00 \%$ \\
\hline Employment & $0.23 \%$ & $2.31 \%$ & $-0.90 \%$ & $1.57 \%$ \\
\hline Population & $0.00 \%$ & $2.31 \%$ & $0.00 \%$ & $1.57 \%$ \\
\hline \multicolumn{5}{|l|}{ NOMINAL TAX REVENUE: } \\
\hline Income Tax and National Insurance & $1.48 \%$ & $2.31 \%$ & $-3.33 \%$ & $-0.71 \%$ \\
\hline Corporation Tax & $2.42 \%$ & $2.72 \%$ & $4.85 \%$ & $3.27 \%$ \\
\hline VAT Revenues & $0.93 \%$ & $1.02 \%$ & $-0.94 \%$ & $-0.42 \%$ \\
\hline Council Tax & $0.29 \%$ & $1.36 \%$ & $\begin{array}{l}-0.53 \% \\
-\end{array}$ & $1.69 \%$ \\
\hline Total taxes/ head & $1.09 \%$ & $-0.61 \%$ & $1.21 \%$ & $-1.30 \%$ \\
\hline Tax-sharing taxes / head & $1.31 \%$ & $-0.39 \%$ & $-2.60 \%$ & $-2.16 \%$ \\
\hline \multicolumn{5}{|l|}{ SCOT GOV SPENDING: } \\
\hline Real Scottish Government Consumption & $-0.84 \%$ & $0.00 \%$ & $2.75 \%$ & $4.16 \%$ \\
\hline
\end{tabular}


Table 4: $\Pi$ Matrix : impact of devolved growth strategies on key endogenous variables, elements of the $\rho$ vector (\% changes)

\begin{tabular}{|c|c|c|c|c|}
\hline \multirow{2}{*}{} & \multicolumn{2}{|c|}{$\begin{array}{c}5 \% \text { export demand } \\
\text { increase }\end{array}$} & $\begin{array}{c}\text { 5\% increase in labour } \\
\text { efficiency }\end{array}$ \\
\cline { 2 - 5 } & Short run & Long run & Short run & Long run \\
\cline { 2 - 5 } & $\pi_{D, S}$ & $\pi_{D, L}$ & $\pi_{S, S}$ & $\pi_{S, L}$ \\
\hline$\frac{\partial \dot{p}}{\partial \pi}$ & 0 & 2.31 & 0 & 1.57 \\
\hline$\frac{\partial \dot{\varepsilon}}{\partial \pi}$ & 0.23 & 0 & -0.90 & 0 \\
\hline$\frac{\partial \dot{\lambda}^{S}}{\partial \pi}$ & 1.08 & -0.39 & -1.70 & -2.16 \\
\hline$\frac{\partial \dot{\lambda}^{F}}{\partial \pi}$ & 0.86 & -0.61 & -0.31 & -1.30 \\
\hline
\end{tabular}

The dot notation represents the proportionate change in the variable. 
Table 5: Q Matrix: Impacts on devolved budgets of local growth strategies across devolved fiscal schemes (\% changes)

\begin{tabular}{|c|c|c|c|c|c|}
\hline \multicolumn{2}{|c|}{} & \multicolumn{2}{c|}{$5 \%$ export demand increase } & 5\% increase in labour efficiency \\
\cline { 3 - 6 } \multicolumn{2}{|c|}{} & Short run & Long run & Short run & Long run \\
\hline \multirow{3}{*}{ Block grant schemes } & $b_{B}$ & 0.00 & 0.00 & 0.00 & 0.00 \\
\cline { 2 - 6 } & $b_{B C}$ & 0.00 & 2.31 & 0.00 & 1.57 \\
\hline \multirow{2}{*}{ Tax sharing } & $b_{S}$ & 0.48 & 0.71 & -0.96 & -0.22 \\
\cline { 2 - 6 } & $b_{S C}$ & 0.48 & -0.14 & -0.96 & -0.80 \\
\hline Full Tax Autonomy & $b_{F}$ & 1.61 & 2.53 & -1.79 & 0.40 \\
\hline
\end{tabular}

Table 6: GDP impacts across policies, time scales and fiscal schemes

\begin{tabular}{|c|c|c|c|c|c|}
\hline \multicolumn{2}{|c|}{} & \multicolumn{2}{c|}{$5 \%$ export demand increase } & \multicolumn{2}{c|}{ 5\% increase in labour efficiency } \\
\cline { 3 - 6 } \multicolumn{2}{|c|}{} & Short run & Long run & Short run & Long run \\
\hline \multirow{2}{*}{ Block grant schemes } & $b_{B}$ & 0.19 & 2.50 & 2.19 & 5.80 \\
\cline { 2 - 6 } & $b_{B C}$ & 0.19 & 3.37 & 2.19 & 6.42 \\
\hline \multirow{2}{*}{ Tax sharing } & $b_{S}$ & 0.23 & 2.79 & 2.09 & 5.76 \\
\cline { 2 - 6 } & $b_{S C}$ & 0.23 & 2.49 & 2.09 & 5.58 \\
\hline Fiscal Tax Autonomy & $b_{F}$ & 0.32 & 3.47 & 2.01 & 5.96 \\
\hline
\end{tabular}


Table 7: Employment impacts across policies, time scales and fiscal schemes

\begin{tabular}{|c|c|c|c|c|c|}
\hline & & \multicolumn{2}{|c|}{ 5\% export demand increase } & \multicolumn{2}{|c|}{$5 \%$ increase in labour efficiency } \\
\hline & & Short run & Long run & Short run & Long run \\
\hline \multirow{2}{*}{$\begin{array}{l}\text { Block grant } \\
\text { schemes }\end{array}$} & $b_{B}$ & 0.23 & 2.31 & -0.90 & 1.57 \\
\hline & $b_{B C}$ & 0.23 & 3.35 & -0.90 & 2.28 \\
\hline \multirow[t]{2}{*}{ Tax sharing } & $b_{S}$ & 0.29 & 2.65 & -1.02 & 1.52 \\
\hline & $b_{S C}$ & 0.29 & 2.29 & -1.02 & 1.32 \\
\hline Full Tax Autonomy & $b_{F}$ & 0.43 & 3.47 & -1.14 & 1.74 \\
\hline
\end{tabular}

